\title{
openheart Predictors of early mortality after transcatheter aortic valve implantation
}

\author{
Didrik Kjønås, ${ }^{1}$ Gry Dahle, ${ }^{2}$ Henrik Schirmer, ${ }^{\circledR 3,4}$ Siri Malm, ${ }^{5}$ Jo Eidet, ${ }^{6}$ \\ Lars Aaberge, ${ }^{7}$ Terje Steigen, ${ }^{1,8}$ Svend Aakhus, ${ }^{9,10}$ Rolf Busund, ${ }^{8,11}$ Assami Rösner ${ }^{1}$
}

To cite: Kjønås D, Dahle G, Schirmer $\mathrm{H}$, et al. Predictors of early mortality after transcatheter aortic valve implantation. Open Heart 2019;6:e000936. doi:10.1136/ openhrt-2018-000936

Received 11 0ctober 2018 Revised 23 March 2019 Accepted 1 April 2019
Check for updates

(C) Author(s) (or their employer(s)) 2019. Re-use permitted under CC BY-NC. No commercial re-use. See rights and permissions. Published by BMJ.

For numbered affiliations see end of article.

Correspondence to Dr Henrik Schirmer; henrik. schirmer@medisin.uio.no

\section{ABSTRACT}

Objectives To investigate whether preoperative echocardiographic evaluation of ventricular function, especially right ventricular systolic and diastolic parameters including speckle-tracking analysis, could aid in the prediction of 30-day mortality after transcatheter aortic valve implantation (TAVI) in patients with aortic stenosis.

Methods This is a prospective observational cohort study including 227 patients accepted for TAVI at the University Hospital of North Norway and Oslo University Hospital from February 2010 through June 2013. All patients underwent preoperative transthoracic echocardiography with retrospective speckle-tracking analysis. Primary endpoint was all-cause 30 -day mortality.

Results All-cause 30-day mortality was $8.7 \%(n=19)$. Independent predictors of 30-day mortality were systolic pulmonary arterial pressure (SPAP) $>60 \mathrm{~mm} \mathrm{Hg}$ (HR: $7.7,95 \% \mathrm{Cl}: 1.90$ to 31.3$)$, heart failure (HR: $2.9,95 \% \mathrm{Cl}$ : 1.1 to 7.78 ), transapical access (HR: $3.8,95 \% \mathrm{Cl}: 1.3$ to 11.2 ), peripheral artery disease (HR: $6.0,95 \% \mathrm{Cl}: 2.0$ to 18.0 ) and body mass index (HR: $0.73,95 \% \mathrm{Cl}: 0.61$ to 0.87 ). C-statistic for the model generated was 0.91 ( $95 \%$ Cl: 0.85 to 0.98). Besides elevated SPAP, no other echocardiographic measurements were found to be an independent predictor of early mortality.

Conclusion Except for elevated systolic pulmonary artery pressure, our data suggests that clinical rather than echocardiographic parameters are useful predictors of 30-day mortality after TAVI.

\section{INTRODUCTION}

Transcatheter aortic valve implantation (TAVI) has become a treatment option for a growing number of patients with aortic stenosis (AS) with intermediate to high risk for surgical aortic valve replacement (SAVR). ${ }^{1}$ However, there are still uncertainties about risk factors of early mortality for these patients. Identifying predictors of early mortality is important in order to improve patient selection and to give patients a better basis for informed consent. TAVI is now performed in patients with intermediate risk for $\mathrm{SAVR}^{2}$ and there are ongoing studies even in low-risk patients (NOTION-2/ NCT02825134, PARTNER 3/NCT02675114, Medtronic Evolut Transcatheter Aortic

\section{Key questions}

What is already known about this subject?

- Prediction of early mortality after transcatheter aortic valve implantation (TAVI) is still imprecise.

What does this study add?

- Despite a thorough preoperative echocardiographic evaluation of left and right ventricular function, including speckle-tracking analysis, our data suggest that clinical parameters are more useful than echocardiographic measurements as predictors of early mortality after TAVI.

How might this impact clinical practice?

- When evaluating patients for TAVI, our data suggest that clinical rather than echocardiographic parameters are more useful in predicting early mortality. Whether this remains the case in today's TAVI population, which is younger and with fewer comorbidities, has yet to be determined.

Valve Replacement in Low Risk Patients/ NCT02701283). These patients are still candidates for open surgery where the risk factors are better identified and incorporated into validated risk algorithms. Despite the development of novel TAVI-specific risk algorithms, ${ }^{3-6}$ risk factors specific for TAVI are currently not fully understood. Both established surgical and novel TAVI-specific risk algorithms are comprised primarily of clinical parameters with the exception of systolic pulmonary arterial pressure (SPAP) and ejection fraction (EF). While the evaluation of left ventricular (LV) function on the outcome after TAVI has been extensively studied, ${ }^{78}$ the knowledge of the impact of right ventricular (RV) function on periprocedural outcome is still limited. RV dysfunction is linked to adverse outcome in several cardiovascular conditions including AS and heart failure. ${ }^{910}$ The aim of our study was to investigate whether preoperative echocardiographic evaluation of ventricular function, especially RV systolic and diastolic parameters including speckle-tracking analysis, in 
addition to clinical parameters could aid in the prediction of unfavourable early outcome after TAVI.

\section{METHODS}

\section{Study population}

From February 2010 through June 2013, 227 patients from the University Hospital of North Norway Troms $\varnothing$ and Oslo University Hospital Rikshospitalet with severe symptomatic AS accepted for TAVI were included in the study. A multidisciplinary heart team determined the patient suitability for TAVI considering cognitive function and comorbid status of the patient as well as technical feasibility. Patients with inability to give informed consent, life expectancy less than 12 months and low motivation for treatment were not offered TAVI. Primary endpoint was all-cause 30-day mortality classified according to the Valve Academic Research Consortium (VARC)-2 criteria. ${ }^{11}$ The study was approved by the Regional Ethical Committees for Medical Research Ethics, North and South East Norway. All patients gave written informed consent.

\section{Patient characteristics}

Patient demographics, clinical characteristics, periprocedural mortality and complications were obtained from the patients' electronic records. Chronic obstructive pulmonary disease (COPD) was classified according to the global initiative for chronic obstructive lunge disease (GOLD) classification. Patients with COPD of unknown grade were classified as having grade 1 . Previous cerebrovascular events comprised both previous strokes and transient ischaemic attacks. Chronic and paroxysmal atrial fibrillation/flutter was grouped as one variable. Heart failure was defined as physician-documented clinical signs of heart failure in the form of unusual dyspnoea on light exertion, orthopnoea, fluid retention, rales on auscultation or pulmonary oedema on chest X-ray less than 2 weeks prior to TAVI. Peripheral artery disease (PAD) was defined as claudication, previous amputation due to vascular insufficiency, previous reconstructive surgery or percutaneous intervention, abdominal aortic aneurism and/or $>50 \%$ stenosis in a peripheral artery diagnosed by CT or angiographic imaging.

\section{Echocardiography}

All patients underwent preoperative transthoracic echocardiographic evaluation with either an iE33 (S5-1 probe, Philips Medical systems, Andover, MA) or a Vivid E9 (GE Vingmed, Horten, Norway) scanner using a $2.5-3.5 \mathrm{MHz}$ transducer in the left lateral decubital position. Conventional two-dimensional grey-scale images were obtained in the parasternal long-axis and short-axis view, as well as the apical four-chamber, two-chamber and three-chamber views. Left ventricular EF (LVEF) was derived from the Simpson's biplane method. The same two views served to calculate left atrial volumes at end-systole. LV longitudinal function was assessed by mitral annular plane systolic excursion in the septal and lateral mitral ring in the apical four-chamber view. Intraventricular septum thickness in diastole was measured in M-mode images in the parasternal long-axis view. Diastolic LV function was assessed by $\mathrm{E} / \mathrm{A}$ ratio, $\mathrm{E} / \mathrm{e}^{\prime}$ ratio and $\mathrm{E}$ deceleration time. The degree of AS was derived from the mean and peak gradient of the Doppler flow across the aortic valve, as well as the aortic valve area derived by the continuity equation. LV stroke volume, cardiac output and cardiac index were derived from the LV outflow tract (LVOT) diameter and LVOT velocity time integral. The degree of aortic regurgitation was estimated by the size of the regurgitation area by colour Doppler, pressure half-time and diastolic velocities in descending aorta by Dopplerflow signal. The degree of mitral regurgitation (MR) was based on measurement and visual assessment of colour Doppler images, vena contracta and proximal isovelocity surface area.

RV geometry and function were evaluated in an adjusted four-chamber view at the largest transversal diameter of the RV. Systolic RV function was assessed by tricuspid annular peak systolic excursion (TAPSE) and tissue velocity imaging derived tricuspid annular systolic velocity in the basal RV free wall. RV areas were measured in end-diastole and end-systole and used for calculating fractional area change. RV longitudinal diameter in diastole was measured as the distance from the RV apex to the middle of the RV annulus. RV mediolateral diameter in diastole was measured from the intraventricular septum to the RV free wall at the widest part of the RV cavity. SPAP was derived from continuous wave Doppler measurements of tricuspid regurgitation (TR) and respiratory variation of the diameter of the inferior vena cava. When TR gradient was not recorded, SPAP was considered being $<30 \mathrm{~mm} \mathrm{Hg}$ if TR was described by visual assessment as trivial or mild, and 30-60 $\mathrm{mm} \mathrm{Hg}$ when TR was described as moderate.

\section{Strain analyses}

Strain analyses were performed using speckle-tracking software VVI7 (Siemens, Mountain View, CA, USA). Longitudinal LV strain was obtained by analyses of the LV in the apical four-chamber, two-chamber and threechamber views. Longitudinal RV strain was obtained from an apical four-chamber view including segments of the lateral wall only (figure 1). The time point of the aortic valve closure was measured in continuous Doppler registrations of the aortic flow. Global strain peak longitudinal strain values were extracted from strain curves by defining the systolic time interval between R-wave and the time point of aortic valve closure. Strain curves with artefacts due to reverberation, air artefact or insufficient tracking were discarded based on subjective visual assessment. In patients with atrial arrhythmia, strain from three cycles, if available, was obtained and averaged.

\section{TAVI procedure}

All TAVI procedures were performed under general anaesthesia with transfemoral (TF), transaortic (TAo) or transapical (TA) access using either first-generation 


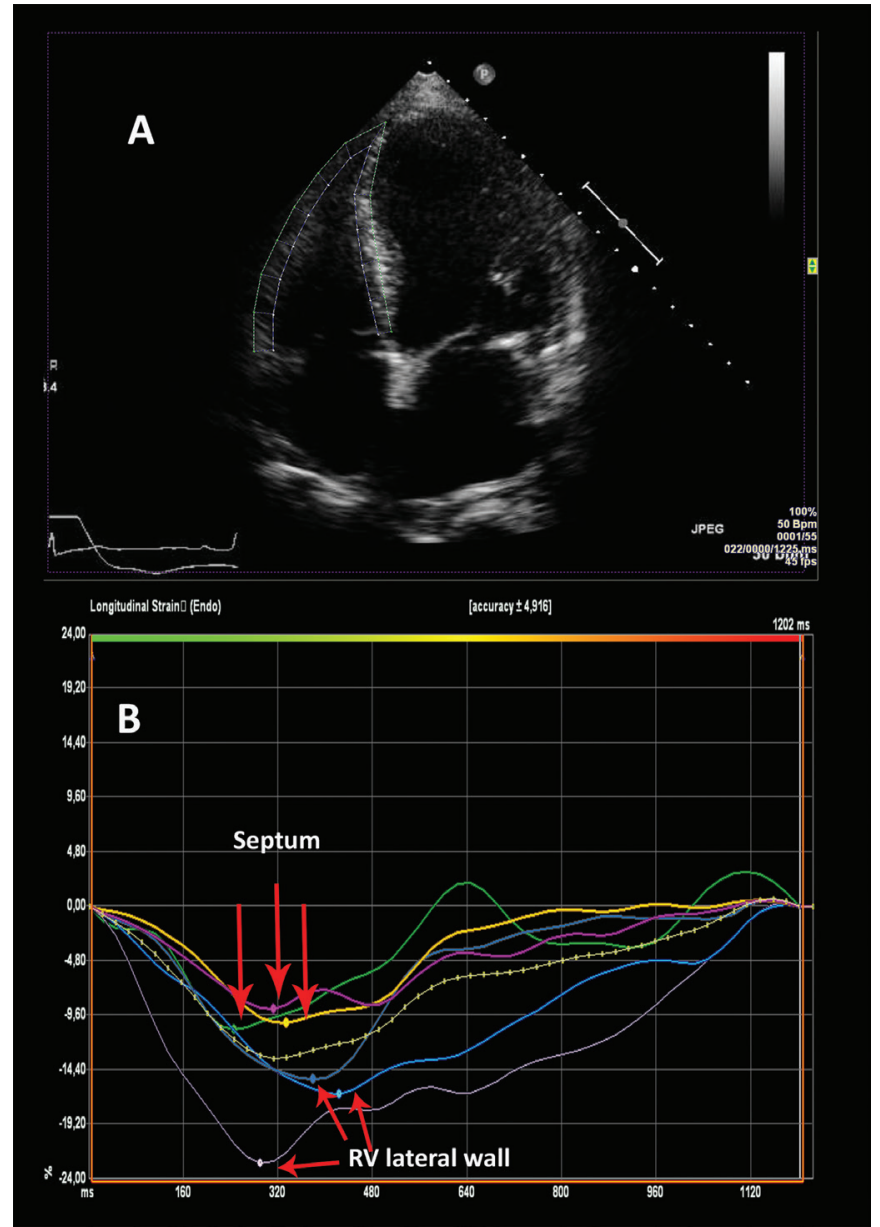

Figure 1 Example of how the RV strain curves are generated from a two-dimensional four-chamber view. RV, right ventricular.

self-expanding Medtronic CoreValve (Medtronic, Minneapolis, MN, USA) or either first- or second-generation Edwards SAPIEN-SAPIEN XT balloon-expandable valve (Edwards Lifesciences, Irvine, CA, USA). Valve size was determined from the aortic annular diameter measured by CT scan reconstruction and/or transesophageal echocardiography. TF access was the preferred modality. TA access was used in the presence of highly calcified and tortious pelvic vessels given acceptable LV and respiratory function. In the presence of inaccessible peripheral vessels and reduced LVEF or COPD, TAo access was used.

\section{Statistical analysis}

The power of the study was calculated using the power calculation package in STATA V.12. We estimated a minimum detectable HR of 1.25 for mortality for a 1-unit change for each echocardiographic variable with a power of $80 \%$ with a $5 \%$ probability of a false-negative result. Data are presented as number $(\%)$ or mean \pm SD as appropriate. Variables between groups were compared using Pearson $\chi^{2}$ or independent t-test for percentages and continuous variables, respectively. Univariable Cox regression analysis was performed for all-cause 30-day mortality. Variables with $\mathrm{p}<0.15$ and deemed clinically relevant were selected and tested for interaction and co-linearity prior to forward and backward multivariable Cox regression analysis. When the interaction terms in the backwards analysis were non-significant, the forward model was used. No imputation for missing data was performed and multivariable analyses performed on all available patients for each analysis. The final model was based on 213 patients. $\mathrm{P}<0.05$ in multivariable analysis was considered significant. C-statistic for predicted 30-day mortality in our cohort was obtained from receiver operating characteristic (ROC) analyses of the predicted probabilities generated from binary logistic regression. All statistical analysis was done using SPSS V.24 (SPSS, Chicago, IL, USA).

\section{Reproducibility}

To determine the interobserver and intraobserver variability of longitudinal strain measurements, recordings from 30 patients were selected at random and another experienced observer repeated the analysis. The same data were reanalysed by the main observer after several months. Intraclass correlation coefficient was used to test interobserver and intra-observer variability.

\section{RESULTS}

The patients' demographics, clinical characteristics and periprocedural results are listed in table 1 and echocardiographic parameters in table 2. Nine patients were excluded from final analysis including three patients who did not undergo TAVI, five cases where preoperative echocardiographic images were not accessible and one patient with aortic insufficiency and not stenosis. The remaining 218 patients were included in the final analysis. All-cause mortality at 30 days was $8.7 \%(\mathrm{n}=19)$. Six $(32 \%)$ of these patients died peroperatively. Postoperatively, $12(63 \%)$ died of cardiovascular causes where three $(16 \%)$ were due to myocardial infarction, five (26\%) secondary to cerebrovascular event and one $(5 \%)$ from either bleeding, worsening heart failure, procedure related or death of unknown cause. One $(5 \%)$ died of non-cardiovascular cause due to subarachnoid haemorrhage secondary to trauma. These patients had significantly lower body mass index (BMI), higher peripheral vascular disease burden, more TA procedures and a higher percentage of patients with SPAP $>60 \mathrm{~mm} \mathrm{Hg}$. The difference in the presence of moderate to severe MR and heart failure was borderline significant between the groups. There was no interaction between variables in our data consequently a forward multivariable regression analysis was performed. All clinically significant variables with $\mathrm{p}<0.15$ in univariable analysis and the result of multivariable analysis are shown in table 3 . All variables included in the final model were highly significant in univariable analysis and maintained significance after multivariable analysis. Figure 2 displays the Kaplan-Meier curves for each independent predictor of all-cause 30-day mortality. 
Table 1 Baseline demographics, clinical characteristics and periprocedural results stratified according to 30-day mortality

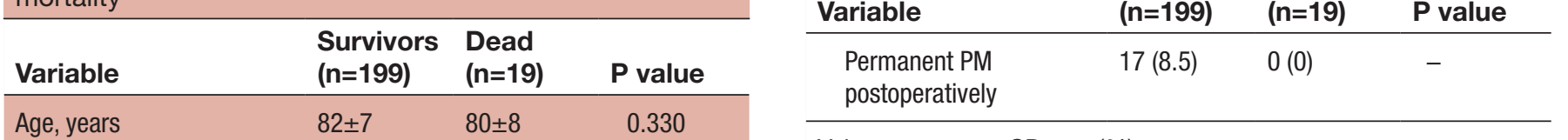

$\begin{array}{llll}\text { Female } & 89(45) & 9(47) & 0.825\end{array}$

\begin{tabular}{llll} 
Body surface area, $\mathrm{m}^{2}$ & $1.8 \pm 0.2$ & $1.7 \pm 0.1$ & 0.005 \\
\hline Body mass index, $\mathrm{kg} / \mathrm{m}^{2}$ & $26 \pm 5$ & $22 \pm 3$ & 0.001 \\
STS score & $5.9 \pm 3.9$ & $8.3 \pm 4.4$ & 0.012 \\
Euroscore 2 & $9.4 \pm 7.2$ & $11.3 \pm 8.8$ & 0.300 \\
NYHA class & & & 0.527 \\
\multicolumn{1}{|l}{} & $29(15)$ & $2(11)$ &
\end{tabular}

\begin{tabular}{llll}
\hline III & $120(60)$ & $10(53)$ & \\
\multicolumn{1}{|c}{ IV } & $50(25)$ & $7(37)$ & \\
Heart failure & $84(42)$ & $12(63)$ & 0.079 \\
Hypertension & $133(67)$ & $15(79)$ & 0.280 \\
Atrial dysrhythmia & $89(45)$ & $11(58)$ & 0.271 \\
$\begin{array}{l}\text { Previous myocardial } \\
\text { infarction }\end{array}$ & $76(38)$ & $6(32)$ & 0.570 \\
\hline
\end{tabular}

\begin{tabular}{|c|c|c|c|}
\hline Previous PCl & $78(39)$ & $9(47)$ & 0.487 \\
\hline Previous cardiac surgery & $93(47)$ & $5(26)$ & 0.087 \\
\hline LBBB & $18(9)$ & $2(11)$ & 0.831 \\
\hline Peripheral artery disease & $66(33)$ & $14(74)$ & $<0.000$ \\
\hline Porcelain aorta & $21(11)$ & $5(26)$ & 0.043 \\
\hline Cerebrovascular disease & $52(26)$ & $6(32)$ & 0.608 \\
\hline $\begin{array}{l}\text { Previous cerebrovascular } \\
\text { event }\end{array}$ & $46(23)$ & $6(32)$ & 0.408 \\
\hline Immunocompromised & $24(12)$ & $4(21)$ & 0.263 \\
\hline Diabetes & $59(30)$ & $3(1.5)$ & 0.201 \\
\hline COPD & $70(35)$ & $8(42)$ & 0.547 \\
\hline eGFR, $\mathrm{ml} / \mathrm{min} / 1.73 \mathrm{~m}^{2}$ & $54 \pm 20$ & $50 \pm 24$ & 0.055 \\
\hline Previous radiation therapy & $8(4)$ & $1(5)$ & 0.795 \\
\hline Access & & & 0.001 \\
\hline Transfemoral & $117(59)$ & $5(26)$ & \\
\hline Transaortic & $27(14)$ & $1(5)$ & \\
\hline Transapical & $55(28)$ & $13(68)$ & \\
\hline Valve type & & & 0.206 \\
\hline Edwards Sapien & $153(77)$ & $17(89)$ & \\
\hline CoreValve & $46(23)$ & $2(11)$ & \\
\hline \multicolumn{4}{|l|}{ Periprocedural results } \\
\hline Intraoperative mortality & - & $6(2.8)$ & \\
\hline Myocardial infarction & $3(1.5)$ & $3(16)$ & $<0.000$ \\
\hline Cerebrovascular event & $6(3)$ & $7(37)$ & $<0.000$ \\
\hline $\begin{array}{l}\text { Major or life-threatening } \\
\text { bleeding }\end{array}$ & $5(2.5)$ & $5(26)$ & $<0.000$ \\
\hline PVL moderate to severe & $18(9)$ & $2(10.5)$ & 0.085 \\
\hline
\end{tabular}

Continued

\section{Table 1 Continued}

Values are mean \pm SD or $n(\%)$

COPD, chronic obstructive pulmonary disease; LBBB, left bundle branch block;NYHA, New York Heart Association; PCI, percutaneous coronary intervention; PM, pacemaker; PVL, paravalvular leakage; STS, society of thoracic surgeons; eGFR, estimated glomerular filtration rate; eGFR, estimated glomerular filtration rate.

SPAP $>60 \mathrm{~mm} \mathrm{Hg}$ was the only independent echocardiographic predictor of early mortality and was present in $21(9.6 \%)$ of the patients. In all, $14(67 \%)$ of these had clinical signs of heart failure prior to surgery, $11(52 \%)$ had COPD and 6 (29\%) had both. Out of the 21 patients with SPAP $>60 \mathrm{~mm} \mathrm{Hg}$, five $(24 \%)$ died within 30 days after treatment, with three having concomitant clinical signs of heart failure, two had COPD and one had both. Heart failure was present in $12(63 \%)$ patients with early mortality compared with $96(44 \%)$ in the whole cohort. Neither New York Heart Association (NYHA) IV nor NYHA III and IV combined were identified as risk factors by univariable analysis. TA access with concomitant PAD was present in $12(63 \%)$ patients who died within 30 days compared with $22(11 \%)$ of the survivors. All of these patients died of cardiovascular causes. BMI was analysed as a continuous variable and was still statistically significant as a predictor of early mortality even when patients with BMI $<20 \mathrm{~kg} / \mathrm{m}^{2}(\mathrm{n}=17)$ were excluded from analyses (HR: $0.79,95 \%$ CI: 0.649 to $0.97, p=0.025$ ). C-statistic for the model generated from multivariable regression analysis in our cohort was 0.91 (95\% CI: 0.85 to 0.98 ).

\section{Reproducibility}

Intraclass correlation coefficient for longitudinal strain measurement was 0.799 (95\% CI 0.695 to 0.868 ) and 0.924 (95\% CI 0.885 to 0.950 ) for interobserver and intraobserver variability, respectively.

\section{DISCUSSION}

All-cause 30 -day mortality rate was $8.7 \%$ which is similar to registry data from the same period. ${ }^{12}$ All but one patient died of cardiovascular causes as defined by the VARC-2 criteria. $^{11}$ In our study, we identified SPAP $>60$ $\mathrm{mm} \mathrm{Hg}$, heart failure, TA access, PAD and BMI as independent predictors of 30-day mortality after TAVI and the model showed high accuracy in ROC analysis correctly allocating $91 \%$ as cases or controls.

Despite a thorough preoperative echocardiographic evaluation, especially of RV systolic and diastolic functional parameters, we did not identify any echocardiographic marker for early mortality except for SPAP $>60$ $\mathrm{mm} \mathrm{Hg}$. 
Table 2 Preoperative echocardiographic parameters stratified according to 30 -day mortality

\begin{tabular}{|c|c|c|c|}
\hline Variable* & $\begin{array}{l}\text { Survivors } \\
(n=199)\end{array}$ & $\begin{array}{l}\text { Dead } \\
(n=19)\end{array}$ & $P$ value \\
\hline LVEF \%, $(n=212)$ & & & 0.751 \\
\hline$\geq 50$ & $100(50)$ & $10(53)$ & \\
\hline $31-49$ & $72(36)$ & $7(37)$ & \\
\hline$\leq 30$ & $22(11)$ & $1(5)$ & \\
\hline LVLS, $(n=198)$ & $-11.1 \pm 3.8$ & $-10.9 \pm 3.6$ & 0.783 \\
\hline $\begin{array}{l}\text { MAPSE septal, } \mathrm{cm} \\
(\mathrm{n}=212)\end{array}$ & $0.70 \pm 0.27$ & $0.67 \pm 0.31$ & 0.691 \\
\hline $\begin{array}{l}\text { MAPSE lateral, } \mathrm{cm} \\
(\mathrm{n}=212)\end{array}$ & $0.99 \pm 0.32$ & $1.0 \pm 0.31$ & 0.844 \\
\hline IVSDd, cm (n=202) & $1.2 \pm 0.3$ & $1.3 \pm 0.3$ & 0.158 \\
\hline AVA, $\mathrm{cm}^{2}(\mathrm{n}=215)$ & $0.63 \pm 0.21$ & $0.58 \pm 0.20$ & 0.407 \\
\hline AVA index, $\mathrm{cm}^{2} / \mathrm{m}^{2}$ & $0.34 \pm 0.11$ & $0.34 \pm 0.11$ & 0.802 \\
\hline
\end{tabular}
$(\mathrm{n}=215)$

\begin{tabular}{|c|c|c|c|}
\hline $\begin{array}{l}\text { AV gradient max, mm } \\
\mathrm{Hg}(\mathrm{n}=215)\end{array}$ & $84 \pm 24$ & $77 \pm 20$ & 0.189 \\
\hline $\begin{array}{l}\text { AV gradient mean, } \\
\mathrm{mm} \mathrm{Hg}(n=215)\end{array}$ & $52 \pm 15$ & $47 \pm 12$ & 0.202 \\
\hline $\begin{array}{l}\text { AV max velocity, } m / s \\
(n=216)\end{array}$ & $453 \pm 67$ & $430 \pm 58$ & 0.162 \\
\hline $\begin{array}{l}\text { SV LVOT index, } \mathrm{ml} / \mathrm{m}^{2} \\
(\mathrm{n}=216)\end{array}$ & $37 \pm 11$ & $35 \pm 12$ & 0.559 \\
\hline LVOT diameter, cm & $2.1 \pm 0.25$ & $2.1 \pm 0.23$ & 0.348 \\
\hline E/é $(n=148)$ & $19.2 \pm 8.1$ & $18.1 \pm 9.7$ & 0.644 \\
\hline$E / A(n=147)$ & $1.1 \pm 0.6$ & $0.8 \pm 0.5$ & 0.159 \\
\hline $\begin{array}{l}\text { MV deceleration time, } \\
m s(n=215)\end{array}$ & $227 \pm 92$ & $221 \pm 89$ & 0.769 \\
\hline MV E, cm/s $(n=215)$ & $96 \pm 34$ & $89 \pm 39$ & 0.454 \\
\hline $\begin{array}{l}\text { LA volume index, } \mathrm{mL} / \\
\mathrm{m}^{2}(\mathrm{n}=204)\end{array}$ & $53 \pm 20$ & $53 \pm 22$ & 0.995 \\
\hline $\begin{array}{l}\text { MR moderate to } \\
\text { severe }(n=209)\end{array}$ & $38(20)$ & $7(37)$ & 0.079 \\
\hline $\begin{array}{l}\text { AR moderate to } \\
\text { severe }(n=213)\end{array}$ & $35(18)$ & $3(16)$ & 0.777 \\
\hline Mitral stenosis & $9(5)$ & $1(5)$ & 0.816 \\
\hline SPAP, mm Hg $(n=215)$ & & & 0.033 \\
\hline$>60$ & $16(8)$ & $5(26)$ & \\
\hline $30-60$ & $120(60)$ & $10(53)$ & \\
\hline$<30$ & $63(32)$ & $4(21)$ & \\
\hline TAPSE, cm (n=204) & $1.6 \pm 0.5$ & $1.7 \pm 0.5$ & 0.405 \\
\hline TASV, $\mathrm{cm} / \mathrm{s}(\mathrm{n}=133)$ & $9.5 \pm 3.2$ & $10.9 \pm 3.3$ & 0.140 \\
\hline FAC, $\%(n=197)$ & $36 \pm 13$ & $37 \pm 9$ & 0.655 \\
\hline RVEDA, $\mathrm{cm}^{2}(\mathrm{n}=197)$ & $20 \pm 5$ & $21 \pm 5$ & 0.469 \\
\hline RVESA, $\mathrm{cm}^{2}(\mathrm{n}=197)$ & $13 \pm 5$ & $13 \pm 3$ & 0.872 \\
\hline $\begin{array}{l}\text { TR moderate to } \\
\text { severe }(n=213)\end{array}$ & $40(21)$ & $5(26)$ & 0.562 \\
\hline RVLS, \% ( $n=171)$ & $-16 \pm 7$ & $-16 \pm 6$ & 0.888 \\
\hline
\end{tabular}

Table 2 Continued

\begin{tabular}{llll}
\hline Variable* $^{*}$ & $\begin{array}{l}\text { Survivors } \\
(n=199)\end{array}$ & $\begin{array}{l}\text { Dead } \\
(n=19)\end{array}$ & P value \\
\hline
\end{tabular}

Values are mean \pm SD or $n(\%)$.

*Numbers in brackets indicate the number of cases where the measurement was available.

$\mathrm{AR}$, aortic regurgitation; $\mathrm{AV}$, aortic valve; $\mathrm{AVA}$, aortic valve area; FAC, fractional area change; IVSDd, intraventricular septum diameter in diastole; LA, left atrium; LVLS, left ventricular longitudinal strain; LVEF, left ventricular ejection fraction; LVOT, left ventricular outflow tract; MAPSE, mitral annular plane systolic excursion; MR, mitral regurgitation; MV, mitral valve; RVEDA, right ventricular end-diastolic area; RVESA, right ventricular end-systolic area; RVLS, right ventricular longitudinal strain; SPAP, systolic pulmonary arterial pressure; SV, stroke vol; TAPSE, tricuspid annular peak systolic excursion; TASV, tricuspid annular systolic velocity; TR, tricuspid regurgitation.

In a study based on 870 patients undergoing TAVI, Testa $e t$ al found that patients with TAPSE $<10 \mathrm{~mm}$ had increased risk of mortality at 30 days ${ }^{13}$ in contrast to two other studies where TAPSE was not found to predict early mortality. ${ }^{1415}$ Both RV dilation and reduced TAPSE have been linked to increased risk of long-term mortality. ${ }^{13141617}$ Barvalia et al found TR to be an independent risk factor for early mortality after TAVI. ${ }^{18}$ To the best of our knowledge, no other studies have identified any RV ventricular functional parameter as independent risk factor for early mortality besides elevated SPAP. The number of previous studies evaluating the effects of RV function on periprocedural outcome is low and the RV functional parameters included are often incomplete. Based on our results, the addition of speckle-tracking analysis did not yield any additional benefit in terms of evaluating the effect of RV nor LV function on early mortality.

\section{Pulmonary hypertension}

In all patients with pulmonary hypertension (PHT) in our cohort, we observed the two most common reasons for this condition; either COPD, heart failure or both. COPD has been identified as an important comorbid factor in patients undergoing TAVI with $\mathrm{PHT}^{19}{ }^{19}$ In contrast to large registry studies, we did not identify COPD as an independent predictor for early mortality. ${ }^{4-6}$ While mild PHT might be associated with reversible increased PAP in heart failure, markedly elevated PAP probably indicates an irreversible condition in patients with heart failure that might not improve after TAVI. Irreversible PHT causes reduced cardio-circulatory reserve resulting in impaired ability to increase stroke volume and cardiac output. As a consequence, patients undergoing TAVI might have inadequate circulatory compensatory mechanism during and after the intervention in response to rapid load changes, anaesthesia and rapid pacing. Our finding of marked PHT as an independent risk factor for early mortality after TAVI is in accordance with data from several registry studies. ${ }^{3-6}$ 
Table 3 Results of univariable and multivariable analysis for all-cause 30-day mortality

\begin{tabular}{|c|c|c|c|c|c|c|}
\hline \multirow[b]{2}{*}{ Variable } & \multicolumn{3}{|c|}{ Univariable } & \multicolumn{3}{|c|}{ Multivariable } \\
\hline & $P$ value & HR & $95 \% \mathrm{Cl}$ & $P$ value & HR & $95 \% \mathrm{Cl}$ \\
\hline Body mass index, $\mathrm{kg} / \mathrm{m}^{2}$ & $<0.000$ & 0.78 & 0.68 to 0.90 & $<0.000$ & 0.73 & 0.61 to 0.87 \\
\hline Heart failure & 0.083 & 2.78 & 0.90 to 5.80 & 0.03 & 2.95 & 1.11 to 7.78 \\
\hline Access & 0.004 & & & 0.017 & & \\
\hline Transfemoral & & Ref & & & Ref & \\
\hline Transaortic & 0.905 & 0.88 & 0.10 to 7.51 & 0.614 & 0.57 & 0.06 to 5.14 \\
\hline Transapical & 0.011 & 4.98 & 1.78 to 13.99 & 0.015 & 3.8 & 1.29 to 11.16 \\
\hline SPAP, $\mathrm{mm} \mathrm{Hg}$ & 0.053 & & & 0.004 & & \\
\hline$<30$ & & Ref & & & Ref & \\
\hline $30-60$ & 0.737 & 1.22 & 0.38 to 3.89 & 0.688 & 1.28 & 0.39 to 4.14 \\
\hline$>60$ & 0.038 & 4.03 & 1.08 to 14.99 & 0.004 & 7.77 & 1.90 to 31.28 \\
\hline Peripheral artery disease & 0.002 & 5.16 & 1.86 to 14.34 & 0.002 & 5.95 & 1.97 to 17.99 \\
\hline MR moderate to severe & 0.091 & 2.24 & 0.88 to 5.68 & NS & - & - \\
\hline COPD & 0.065 & 1.40 & 1.01 to 7.79 & NS & - & - \\
\hline Previous cardiac surgery & 0.101 & 0.43 & 0.15 to 1.18 & NS & - & - \\
\hline eGFR ml/min/1.73 $\mathrm{m}^{2}$ & 0.055 & 0.98 & 0.96 to 1.00 & NS & - & - \\
\hline Porcelain aorta & 0.048 & 2.81 & 1.01 to 7.79 & NS & - & - \\
\hline
\end{tabular}

COPD, chronic obstructive pulmonary disease; MR, mitral regurgitation;NS, non-significant; SPAP, systolic pulmonary arterial pressure; eGFR, estimated glomerular filtration rate.

\section{Heart failure}

Clinical signs of heart failure within 2 weeks prior to TAVI was an independent predictor of early mortality in our cohort. Opposed to physical and radiological signs of heart failure, the NYHA classification is based on limitations on physical activity. The majority of our patients were classified as NYHA III-IV. The distinction between classes III and IV is subjective and might in addition to cardiac have its origin in respiratory, musculoskeletal and mental causes, or a combination of these factors. This might suggest that in this setting objective clinical signs of heart failure could be more helpful than only functional limitation when evaluating symptom severity. Furthermore, it may also indicate that optimisation of medical heart failure treatment prior to surgery might be a key factor to improve outcome.

\section{Access and PAD}

Central access, especially TA access, has emerged as a significant risk factor for early mortality compared with TF access. ${ }^{46}$ Compared with patients receiving TF-TAVI, these patients have a higher burden of comorbidities and higher preoperative risk based on preoperative surgical risk algorithms. ${ }^{20-22}$ Central access is also more invasive and requires surgical access via a limited thoracotomy or sternotomy, which might impair postoperative respiratory effort secondary to pain. Our cohort had a low number of patients treated with TAo access, rendering to low power to assess if it is a significant risk factor. TF access depends on anatomical accessibility and adequate diameter of femoral and iliac vessels to facilitate instrumentation of introducer sheaths, but the presence of PAD does not necessarily result in a central access. If there are adequate diameter of access site vessels and satisfactory vascular anatomy proximally, TF access can be employed. Despite patients treated with central access having a higher burden of comorbidities, including PAD that might impact choice of access site, our data suggest that access and PAD are independent risk factors for early mortality. This might be due to factors related to the procedure itself, a consequence of patient selection or both. Whatever the reason, choice of access site is an important factor in risk evaluation when considering patients for TAVI as it seems to convey increased risk in itself. In addition to being a factor in the selection of access site, PAD reflects the patients' vascular disease burden and has been shown to increase the risk of TF-TAVI vascular complications, ${ }^{23}$ which, in turn, has been associated with increased 30-day mortality. ${ }^{24}{ }^{25} \mathrm{~A}$ meta-analysis by D'Ascenzo et alshowed that the extent of coronary artery disease and the results of percutaneous coronary intervention (PCI), evaluated by Syntax Score and residual Syntax Score, respectively, were predictive of 1-year but not 30-day mortality. ${ }^{26}$ Despite not calculating Syntax Score in our cohort, we found no mortality difference between the groups with respect to previous myocardial infarction or PCI. In accordance with the aforementioned study, we found neither PCI nor previous myocardial infarction to be predictive of 30-day mortality. Although all patients in our cohort underwent TAVI under general anaesthesia, TF-TAVI is at present often 

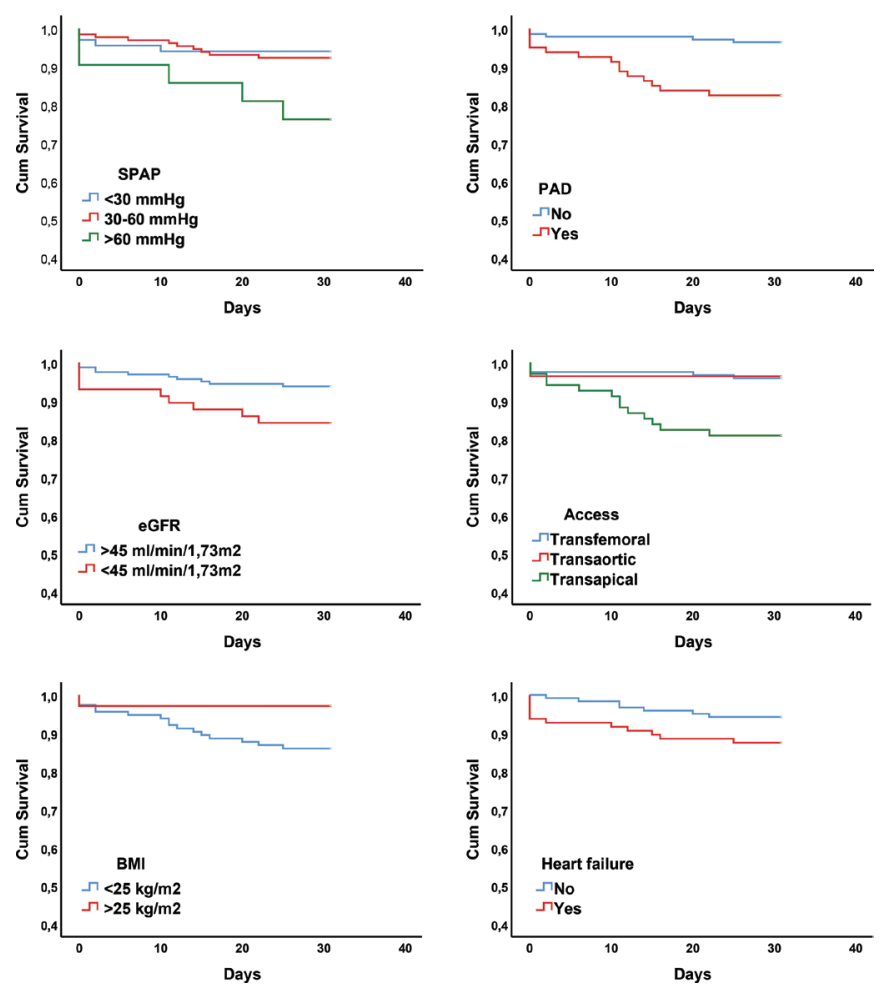

Figure 2 Kaplan-Meier curves for each independent predictor stratified according to 30-day all-cause mortality. Heart failure defined as clinical signs of heart failure in the form of unusual dyspnoea on light exertion, orthopnoea, fluid retention, rales on auscultation, or pulmonary oedema on chest X-ray less than 2 weeks prior to TAVI. BMI, body mass index; eGFR, estimated glomerular filtration rate; PAD, peripheral artery disease; SPAP, systolic pulmonary arterial pressure; TAVI, transcatheter aortic valve implantation,

done in local anaesthesia and sedation, which has been shown to reduce 30 -day mortality after TAVI. ${ }^{27}$ Although TA-TAVI being a valid option in clinical practice when TF access is not technically feasible, TF-TAVI should be considered the preferred modality.

\section{BMI}

The term 'obesity paradox' was first used to describe the increased early mortality after PCI in patients with low $\mathrm{BMI}^{28}$ and has also been observed in patients treated with TAVI. ${ }^{29-31}$ The VARC-2 consensus document states that frailty, where $\mathrm{BMI}<20 \mathrm{~kg} / \mathrm{m}^{2}$ is a component, is among the risk factors not captured by traditional surgical risk scores. ${ }^{11}$ BMI might be a possible surrogate for frailty or cardiac cachexia in the TAVI population, but there are conflicting data whether low BMI confers risk in itself compared with the apparently protective effect of obesity. ${ }^{32} 3$ In our cohort, BMI was analysed as a continuous variable and was still statistically significant even when patients with low BMI $\left(<20 \mathrm{~kg} / \mathrm{m}^{2}\right)$ were excluded. Although we had few patients that were morbidly obese, our data suggest better survival with increasing BMI supporting the obesity paradox.

\section{Limitations}

Compared with large registry studies, our study included patients from only two centres and was performed during an early stage after the implementation of TAVI as a treatment option. This makes our findings less generalisable at present, and the results may be affected by center-and operator experience in addition to improvements in operative technique and equipment. Our inclusion criteria were rather strict and patients with lower preoperative risk are now offered TAVI, which may alter the risk considerably. Our univariable regression analysis resulted in several significant variables with the risk of low power in a relatively small cohort. This in general could be viewed as a limitation. However, since a forward multivariable regression analysis was performed and all variables were highly significant, stricter inclusion criteria would not have changed the final model.

\section{CONCLUSION}

With the exception of elevated SPAP, our data suggest that clinical rather than echocardiographic parameters are more useful as predictors of 30-day mortality after TAVI. We identified SPAP $>60 \mathrm{~mm} \mathrm{Hg}$, heart failure, TA access, PAD and BMI as independent predictors of 30-day mortality after TAVI. Our data suggest that these factors should be taken into consideration when evaluating highrisk patients for TAVI.

\section{Author affiliations}

${ }^{1}$ Department of Cardiology, University Hospital of North Norway, Troms $\emptyset$, Norway ${ }^{2}$ Department of Cardiothoracic Surgery, Oslo University Hospital Rikshospitalet, Oslo, Norway

${ }^{3}$ Department of Cardiology, Akershus University Hospital, Lørenskog, Norway ${ }^{4}$ Institute of Clinical Medicine, University of Oslo

, Oslo, Norway

${ }^{5}$ Department of Cardiology, University Hospital of North Norway, Harstad, Norway ${ }^{6}$ Department of Anaesthesiology, Oslo University Hospital Rikshospitalet, Oslo, Norway

${ }^{7}$ Department of Cardiology, Oslo University Hospital Rikshospitalet, Oslo, Norway ${ }^{8}$ Institute of Clinical Medicine, The Arctic University of Norway, UiT, Troms $\emptyset$, Norway ${ }^{9}$ Department of Circulation and Medical Imaging, Faculty of Medicine and Health Science, Norwegian University og Science and Technology, NTNU, Trondheim, Norway

${ }^{10}$ Department of Cardiology, Saint Olavs University Hospital, Trondheim, Norway ${ }^{11}$ Department of Cardiothoracic and Vascular Surgery, Universitetssykehuset NordNorge, Tromso, Norway

Contributors AR, HS, RB and SA designed the protocol. AR, SA, GD, JE, SM, $\mathrm{LA}$ and $\mathrm{RB}$ collected the data. DK performed the data extraction and the offline calculations. DK did the statistical analysis and drafting of the first version of the manuscript in close cooperation with AR, HS, RB and SA. All authors contributed to the revision and all aspects of the final manuscript, and are guarantors of the study.

Funding DK received grant from the Regional Health Authorities of North Norway.

Competing interests Rolf Busund is a consultant for Edwards Lifesciences and has received speakers fee from Abbott. Lars Aaberge is a proctor for Edwards Lifesciences.

Patient consent for publication Obtained.

Ethics approval Regional Ethical Committees for Medical Research Ethics, North and South East Norway.

Provenance and peer review Not commissioned; externally peer reviewed. Data sharing statement Data are available upon reasonable request. 
Open access This is an open access article distributed in accordance with the Creative Commons Attribution Non Commercial (CC BY-NC 4.0) license, which permits others to distribute, remix, adapt, build upon this work non-commercially, and license their derivative works on different terms, provided the original work is properly cited, appropriate credit is given, any changes made indicated, and the use is non-commercial. See: http://creativecommons.org/licenses/by-nc/4.0/.

\section{REFERENCES}

1. Leon MB, Smith CR, Mack M et al. Transcatheter aortic-valve implantation for aortic stenosis in patients who cannot undergo surgery. N Engl J Med 2010;363:1597-607.

2. Leon MB, Smith CR, Mack MJ, et al. Transcatheter or surgical aortic-valve replacement in intermediate-risk patients. $N$ Engl J Med 2016;374:1609-20.

3. Capodanno D, Barbanti M, Tamburino C, et al. A simple risk Tool (the OBSERVANT Score) for prediction of 30-day mortality after transcatheter aortic valve replacement. Am J Cardiol 2014:113:1851-8

4. lung $B$, Laouénan $C$, Himbert D, et al. Predictive factors of early mortality after transcatheter aortic valve implantation: individual risk assessment using a simple score. Heart 2014;100:1016-23.

5. Kötting J, Schiller W, Beckmann A, et al. German aortic valve score: a new scoring system for prediction of mortality related to aortic valve procedures in adults. Eur J Cardiothorac Surg 2013;43:971-7.

6. Halkin A, Steinvil A, Witberg G, et al. Mortality prediction following transcatheter aortic valve replacement: a quantitative comparison of risk scores derived from populations treated with either surgical or percutaneous aortic valve replacement. the Israeli TAVR registry risk model accuracy assessment (IRRMA) study. Int J Cardiol 2016;215:227-31.

7. Schaefer U, Zahn R, Abdel-Wahab M, et al. Comparison of outcomes of patients with left ventricular ejection fractions $\leq 30 \%$ versus $\geq 30 \%$ having transcatheter aortic valve implantation (from the German Transcatheter Aortic Valve Interventions Registry). Am J Cardiol 2015;115:656-63.

8. Ferrante G, Presbitero P, Pagnotta P, et al. Impact of severe left ventricular dysfunction on mid-term mortality in elderly patients undergoing transcatheter aortic valve implantation. J Geriatr Cardiol 2016:13:290-8.

9. Galli E, Guirette Y, Feneon D, et al. Prevalence and prognostic value of right ventricular dysfunction in severe aortic stenosis. European Heart Journal - Cardiovascular Imaging 2015;16:531-8.

10. Kjaergaard J, Akkan D, Iversen KK, et al. Right ventricular dysfunction as an independent predictor of short- and long-term mortality in patients with heart failure. Eur J Heart Fail 2007;9:610-6.

11. Kappetein AP, Head SJ, Généreux P, et al. Updated standardized endpoint definitions for transcatheter aortic valve implantation: the valve academic research Consortium-2 consensus document. J Am Coll Cardiol 2012;60:1438-54.

12. Mack MJ, Brennan JM, Brindis R, et al. Outcomes following transcatheter aortic valve replacement in the United States. JAMA 2013;310:2069-77.

13. Testa L, Latib A, De Marco F, et al. The failing right heart: implications and evolution in high-risk patients undergoing transcatheter aortic valve implantation. Eurolntervention 2016;12:1542-9.

14. Griese DP, Kerber S, Barth S, et al. Impact of right and left ventricular systolic dysfunction on perioperative outcome and long-term survival after transcatheter aortic valve replacement. J Interv Cardiol 2017;30:217-25

15. Poliacikova P, Cockburn J, Pareek N, et al. Prognostic impact of preexisting right ventricular dysfunction on the outcome of transcatheter aortic valve implantation. J Invasive Cardiol 2013;25:142-5.
16. Schwartz LA, Rozenbaum Z, Ghantous E, et al. Impact of right ventricular dysfunction and tricuspid regurgitation on outcomes in patients undergoing transcatheter aortic valve replacement. J Am Soc Echocardiogr 2017;30:36-46.

17. Ito S, Pislaru SV, Soo WM, et al. Impact of right ventricular size and function on survival following transcatheter aortic valve replacement. Int J Cardiol 2016;221:269-74.

18. Barvalia M, Tayal R, Cohen M, et al. Impact of tricuspid valve regurgitation on early outcomes after transcatheter aortic valve replacement. J Heart Valve Dis 2017;26:380-5.

19. Oudiz RJ. Pulmonary hypertension associated with left-sided heart disease. Clin Chest Med 2007;28:233-41.

20. Ghatak A, Bavishi C, Cardoso RN, et al. Complications and Mortality in Patients Undergoing Transcatheter Aortic Valve Replacement With Edwards SAPIEN \& SAPIEN XT Valves: A Meta-Analysis of World-Wide Studies and Registries Comparing the Transapical and Transfemoral Accesses. J Interv Cardiol 2015;28:266-78.

21. Panchal HB, Ladia V, Desai S, et al. A meta-analysis of mortality and major adverse cardiovascular and cerebrovascular events following transcatheter aortic valve implantation versus surgical aortic valve replacement for severe aortic stenosis. Am J Cardio 2013;112:850-60.

22. Koifman E, Magalhaes M, Kiramijyan S, et al. Impact of transfemoral versus transapical access on mortality among patients with severe aortic stenosis undergoing transcatheter aortic valve replacement. Cardiovasc Revasc Med 2016;17:318-21.

23. Toggweiler S, Gurvitch R, Leipsic J, et al. Percutaneous aortic valve replacement. J Am Coll Cardiol 2012;59:113-8.

24. Hayashida K, Lefèvre $T$, Chevalier $B$, et al. Transfemoral aortic valve implantation. JACC Cardiovasc Interv 2011;4:851-8.

25. Moretti C, D'Amico M, D'Ascenzo F, et al. Impact on prognosis of periprocedural bleeding after TAVI: mid-term follow-up of a multicenter prospective study. J Interv Cardiol 2014;27:293-9.

26. D'Ascenzo F, Verardi R, Visconti M, et al. Independent impact of extent of coronary artery disease and percutaneous revascularisation on 30-day and one-year mortality after TAVI: a meta-analysis of adjusted observational results. Eurolntervention 2018;14:e1169-77.

27. Villablanca PA, Mohananey D, Nikolic K, et al. Comparison of local versus general anesthesia in patients undergoing transcatheter aortic valve replacement: a meta-analysis. Catheter Cardiovasc Interv 2018:91:330-42.

28. Ellis SG, Elliott J, Horrigan M, et al. Low-normal or excessive body mass index: newly identified and powerful risk factors for death and other complications with percutaneous coronary intervention. Am J Cardiol 1996;78:642-6.

29. van der Boon RMA, Chieffo A, Dumonteil N, et al. Effect of body mass index on short- and long-term outcomes after transcatheter aortic valve implantation. Am J Cardiol 2013;111:231-6.

30. Yamamoto M, Mouillet G, Oguri A, et al. Effect of body mass index on 30- and 365-day complication and survival rates of transcatheter aortic valve implantation (from the FRench Aortic National CoreValve and Edwards 2 [FRANCE 2] registry). Am J Cardiol 2013;112:1932-7.

31. ALICE (All-Literature Investigation of Cardiovascular Evidence) Group, Takagi H, Umemoto T. "Obesity paradox" in transcatheter aortic valve implantation. J Cardiovasc Surg 2017;58:113-20.

32. Yamamoto $\mathrm{M}$, Hayashida $\mathrm{K}$, Watanabe $\mathrm{Y}$, et al. Effect of body mass index \&lt;20 kg/m(2) on events in patients who underwent transcatheter aortic valve replacement. Am J Cardiol 2015:115:227-33.

33. Koifman E, Kiramijyan S, Negi SI, et al. Body mass index association with survival in severe aortic stenosis patients undergoing transcatheter aortic valve replacement. Catheter Cardiovasc Interv 2016;88:118-24. 